\title{
Yaşlı Bireylerde Uyku Sorunlarını Gidermeye Yönelik Nonfarmakolojik Müdahaleler: Sistematik Derleme $\infty$
}

\author{
Gülfidan BASSER ${ }^{1}$, Filiz HiSAR ${ }^{2}$
}

\section{Öz}

Amaç: Bu çalışmada yaşı bireylerde uyku sorunlarını gidermeye yönelik nonfarmakolojik müdahaleleri içeren randomize kontrollü çalışmaların sistematik olarak incelenmesi amaçlanmıştır. Gereç ve Yöntem: Çalışma için, Nisan-Haziran 2019 tarihleri arasında; Google Akademik, Wiley, Web of Science, Springer Link, Scopus, Science Direct, Clinical Key, CINAHL, PubMed, Ulusal Tez Merkezi (https://tez.yok.gov.tr/UlusalTezMerkezi/), Dergipark ve Ulakbim arama motorlarından tarama yapılmıştır. Sistematik derlemeye Ocak 2014-Mayıs 2019 yıllarında yayımlanmış, yaşlılıkta uyku sorunlarına yönelik kullanılan nonfarmakolojik yöntemleri bildiren randomize kontrollü çalışmalar dahil edilmiştir.

Bulgular: Tarama sonucunda altı çalışma ile veri çekme işlemi gerçekleştirilmiş̧ir. İncelenen çalışmalarda yaşlı bireylerde uyku ile ilgili görülen sorunlara yönelik kullanılan yöntemler; bilişsel davranışçı terapi, müzik terapi, anımsama terapisi, fitoterapi (papatya özü), akupres, refleksoloji ve ayak banyosu olarak sıralanmaktadır.

Sonuç: Sonuç olarak bu sistematik derlemeye dahil edilen çalışmalarda uygulanan yöntemlerin hiçbir yan etkisi bildirilmemiştir. Kullanılan yöntemlerin hepsinde uyku kalitesinde iyileşmeler olduğu görülmektedir. Bu yöntemler uyku sorunlarını gidermeye yönelik kolaylıkla kullanılacak yöntemler olmakla birlikte bu çalışmaların tekrarlanıp daha güçlü kanıtların sunulmasına intiyaç vardır.

Anahtar kelimeler: Kanıta dayalı uygulamalar, nonfarmakolojik müdahale, uyku, yaşıı

\begin{abstract}
Nonpharmacological Interventions towards the Sleep Problems in the Elderly: A Systematic Review

Aim: This study aims to perform a systematic review of the randomized controlled studies conducted on nonpharmacological interventions to relieve sleep problems in the elderly.

Material and Methods: Google Scholar, Wiley, Web of Science, Springer Link, Scopus, Science Direct, Clinical Key, CINAHL, PubMed, National Thesis Center (https://tez.yok.gov.tr/UlusalTezMerkezi/), Dergipark and Ulakbim databases were searched between April and June 2019. Randomized controlled trials, published between January 2014 and May 2019, reporting nonpharmacological methods used for sleep problems in the elderly were included in the systematic review.

Results: As a result of the database search, six studies were used for data collection. In the studies reviewed, the common methods used for the sleep-related problems in the elderly include cognitive behavioral therapy, music therapy, reminiscence therapy, phytotherapy (chamomile extract), acupressure, reflexology, and foot bath.

Conclusion: As a result, no side effects of the methods applied were reported in the studies included in this systematic review. All of the methods used seem to have improvements in sleep quality. Although these methods are easily used to solve sleep problems, there is a need to repeat these studies and provide stronger evidence.

Keywords: Elderly, evidence-based practice, nonpharmacological intervention, sleep
\end{abstract}

${ }^{1}$ Öğr. Gör., KTO Karatay Üniversitesi Sağlık Hizmetleri Meslek Yüksekokulu, Tıbbi Hizmetler ve Teknikler Bölümü, Konya, Türkiye, E-posta: gulfidan.baser@gmail.com, Tel: 444 1251-7550, ORCID: 0000-0002-0171-4377

2Prof. Dr., Necmettin Erbakan Üniversitesi Hemşirelik Fakültesi, Hemşirelik Bölümü Halk Sağlığı Hemşireliği Anabilim Dalı, Konya, Türkiye, E-posta: filiz.hisar@gmail.com, Tel: +90 33232040 49, ORCID: 0000-0003-0640-0091

Geliş Tarihi: 09 Haziran 2020, Kabul Tarihi: 30 Mart 2021

Atıf/Citation: Başer G, Hisar F. Yaşıı Bireylerde Uyku Sorunlarını Gidermeye Yönelik Nonfarmakolojik Müdahaleler: Sistematik Derleme. Hacettepe Üniversitesi Hemşirelik Fakültesi Dergisi 2021;8(2):178-185. DOI: 10.31125/hunhemsire.966442 


\section{Giriş̧}

Yaşlanma ile birlikte uyku yapısında değişiklikler beklenmektedir. Bu değişiklikler toplam uyku süresi ve uyku sürekliliğinde azalma şeklinde görülmektedir1-3. Uyku sürekliliği, hem uykuya daldıktan sonra uyanma ile hem de uyku başlangıcındaki gecikme artışından dolayı yaşlanmayla birlikte azalmaktadır².

Yaşlı bireylerde uyku bozuklukları prevalansı \%24 ile \%70.4 arasında değişmektedir ${ }^{4-6}$. Uyku bozuklukları, özellikle yaşlı bireylerin zihinsel ve fiziksel sağlıkları üzerinde olumsuz etkilere neden olmaktadır ${ }^{4}$ Gece uyku bozukluğu ve gündüz uykululuk hali olan yaşlı bireylerde olmayanlara göre kognitif fonksiyon bozukluğu görülme riski daha yüksektir? ${ }^{7}$. Altı yıllık bir prospektif çalışmanın sonuçlarına göre gündüz gerçekleşen aşırı uyku halinin yaşlı bireylerde ilk ve tekrarlayan kardiyovasküler hastalıklar riskini artırdığı bildirilmiştir8. Kore'de yapılan bir çalışmada ise yaşlı bireylerin yaklaşık üçte birinin insomniadan muzdarip olduğu ve insomnia hastalarının, özellikle de depresif belirtiler olmak üzere çeşitli komorbid durumlar gösterdiği belirtilmektedir ${ }^{9}$.

Uykunun, homeostazı devam ettirmek gibi önemli bir işlevi vardır $^{10}$. Bu nedenle yaşlı bireylerde uyku bozukluklarına yönelik müdahalelerin bilinmesi hayati önem taşımaktadır. Uyku bozukluklarının çoğunun yönetimi genellikle hem farmakolojik hem de farmakolojik olmayan müdahaleleri içeren çoklu terapötik rejimler gerektirir ${ }^{11}$. Literatürde nonfarmakolojik müdahalelerin ilaç tedavilerine kıyasla yan etkilerinin daha az olduğu belirtilmektedir ${ }^{12-14}$.

Yaşlı bireylerin bakımıyla ilgilenen gruplardan biri de hemşirelerdir. Hemşireler huzurevlerinde ve primer bakım merkezlerinde yaşlılarla çalışmaktadır. Sağıık sektörünün en büyük bölümü olan ve kanıta dayalı pratiğin bir uygulama normu olarak tercüme edilen hemşirelerin, nonfarmakolojik uygulamalar konusundaki kanıtları bilmesi hayati önem taşımaktadır ${ }^{10}$. Bu nedenle bu çalışmada yaşlı bireylerde uyku sorunlarını gidermeye yönelik nonfarmakolojik müdahaleleri içeren randomize kontrollü çalışmaların sistematik olarak incelenmesi amaçlanmıştır. Literatürde bu konuda yapılmış benzer çalışmalar bulunmakla birlikte ${ }^{15,16}$ bu çalışmalar örneklem, tarama zamanı ve uyku kalitesi için özellikle belirtilmiş nonfarmakolojik bir yöntemin etkinliğinin araştırılması gibi özelliklerinden dolayı farklılık göstermektedir. $\mathrm{Bu}$ sistematik derlemenin uyku bozukluklarına yönelik nonfarmakolojik uygulamalar konusunda ortak bir bakış açısı sağlayacağı düşünülmektedir.

\section{Araştırmanın Amacı}

Bu çalışmada yaşı bireylerde uyku sorunlarını gidermeye yönelik nonfarmakolojik müdahaleleri içeren randomize kontrollü çalışmaların sistematik olarak incelenmesi amaçlanmıştır.

Araştırmanın soruları;

1. Yaşlı bireylerde uyku kalitesini etkileyen nonfarmakolojik yöntemler nelerdir?

2. Yaşı bireylerde uyku kalitesini etkileyen nonfarmakolojik yöntemlerin etkinliğinin kanıtları nelerdir?

\section{GEREÇ ve YÖNTEM}

\section{Araştırma Türü}

$\mathrm{Bu}$ çalışmanın türü sistematik derleme olup, sistematik derleme protokolünün oluşturulması ve makalenin yazımında PRISMA Bildirimi'nden yararlanılmıştır ${ }^{17}$.

\section{Tarama stratejisi}

Çalışma için, Nisan-Haziran 2019 tarihleri arasında; Google Akademik, Wiley, Web Of Science, Springer Link, Scopus, Science Direct, Clinical Key, CINAHL, PubMed, Ulusal Tez Merkezi (https://tez.yok.gov.tr/UlusalTezMerkezi/), Dergipark, ve Ulakbim arama motorlarından tarama yapılmıştır. Taramada Türkçe "yaşlı" ve "uyku" veya "uyku kalitesi" ve "randomize kontrollü çalışma" ve "nonfarmakolojik"; İngilizce "elderly" or "older people" and "sleep" or "sleep quality" and "randomized controlled trial" and "nonpharmacologic" anahtar kelimeleri kullanılmıştır. Sistematik derlemeye Ocak 2014-Mayıs 2019 yıllarında yayımlanmış, yaşlııkta uyku sorunlarına yönelik kullanılan nonfarmakolojik yöntemleri bildiren çalışmalar dahil edilmiştir.

\section{Uygunluk Kriterleri}

Bu çalışmaya, 60 yaş ve üstü, Pittsburgh Uyku Kalitesi İndeksi skoru 5'ten büyük olan, uyku sorununa yönelik tıbbi tedavi almayan, bilişsel işlev bozukluğu olmayan bireylerin dahil edildiği, uyku sorunlarına yönelik müdahaleleri içeren, 2014 ve sonrasında yayınlanan randomize kontrollü çalışmalar dahil edilmiştir.

\section{Çalışmaların belirlenmesi ve seçimi}

Bu çalışmaya, Türkçe ve İngilizce olarak yayınlanmış, yaşlı bireylerde uyku bozukluklarına yönelik nonfarmakolojik girişimlerin etkisini bildiren randomize kontrollü araştırma makaleleri alınmıştır. Makale seçim sürecinin ayrıntıları Şekil 1 'de verilmiştir. Bu sistematik derlemede çalışmaların belirlenmesi ve seçimi iki araştırmacı tarafından bağımsız olarak yapılmış ve herhangi bir çalışma hakkında görüş farklıığı olduğunda tartışılarak uzlaşmaya varılmıştır. Başlık ve özete göre yapılan seçimden sonra 28 makale tam metne göre kalite değerlendirmesine alınmıştır.

\section{Çalışmaların metodolojik kalitesinin değerlendirilmesi}

$\mathrm{Bu}$ sistematik derlemeye alınan makalelerin metodolojik kalitesi iki araştırmacı tarafından değerlendirilmiştir. Çalışmada randomize kontrollü araştırmaların kalitesini değerlendirmek için "The Joanna Briggs Institute Critical Appraisal tools for use in JBI Systematic Reviews Checklist for Randomized Controlled Trials" kullanılmıştır ${ }^{18}$. Bu, randomize kontrollü araştırma makalelerinin hazırlanması sırasında, makalede yazılması gereken bölümleri gösteren 13 maddeden oluşan bir kontrol listesidir. Kalitatif senteze dahil edilen çalışmaların sayısı 6'dir (Şekil 1).

\section{Verilerin çekilmesi ve analizi}

Araştırma verilerini elde etmek için araştırmacılar tarafından geliştirilen veri çekme aracı kullanılmıştır (Tablo 1). Bu veri çekme aracı ile sistematik derlemeye alınan çalışmaların yapıldığı ve yayınlandığı yıl, çalışma deseni, veri toplama aracı, araştırmanın yapıldığı ülke, çalışma alanı, örneklem hacmi, yaş, uygulanan nonfarmakolojik yöntem ve girişimlerin etkisi hakkındaki verilerin toplanması 
sağlanmıştır. Veri çekme işlemi birinci araştırmacı tarafından bağımsız olarak yapılmış ve ikinci araştırmacı tarafından kontrol edilmiştir.

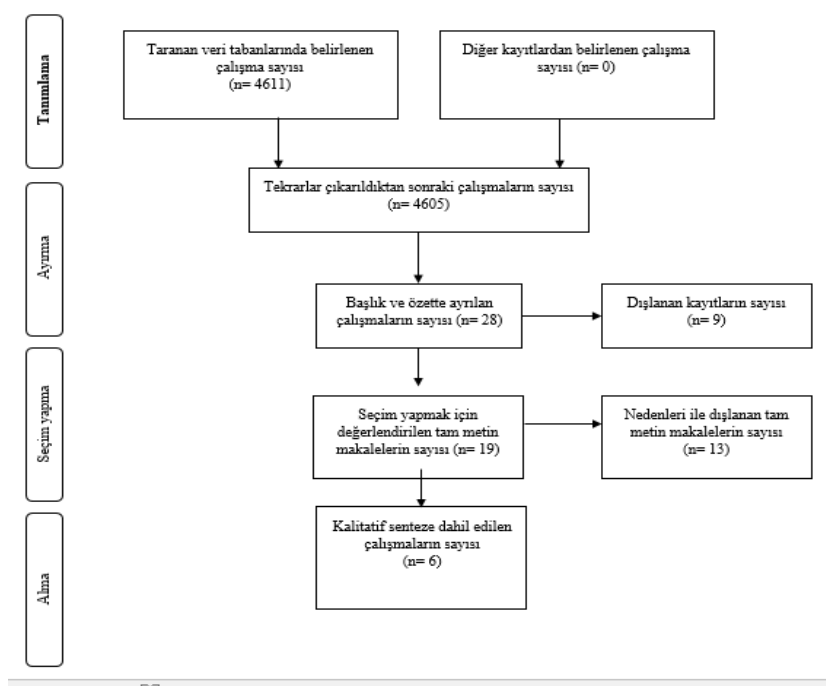

Şekil 1. Çalışmaların Seçimi ve Alınma Süreci

\section{İstatistiksel çözümleme}

Uygulanan yöntem, araştırma deseni ve müdahale sürelerindeki değişiklikler nedeniyle meta-analiz yapılamamış, elde edilen veriler tablolaştırılarak sunulmuştur (Tablo 1).

\section{Araştırmanın Sınırlılıkları}

Bu sistematik derleme için sadece Ingilizce ve Türkçe dillerinde tarama yapılmış olması araştırmanın sınırııı̆ıdır.

\section{BULGULAR}

\section{Tarama bulguları}

Tarama sonucunda başlangıçta 4611 çalışmaya ulaşılmış, tekrar eden çalışmaların çıkarılması ve başlık ve özete göre yapılan seçimden sonra 28 çalışma tam metne göre kalite değerlendirmesine alınmıştır. Kalite değerlendirilmesinden sonra da 6 çalışma ile veri çekme işlemi gerçekleştirilmiştir.

\section{Metodolojik kalite değerlendirme bulguları}

$\mathrm{Bu}$ sistematik derlemeye 13 maddelik Joanna Briggs Institute (JBI) kontrol listesinin en az dokuzunu karşılayan randomize kontrollü çalışmalar dahil edilmiştir.

\section{Çalışmaların özellikleri}

Sistematik derlemeye altı çalışma dahil edilmiştir. Bu çalışmalar 2010-2017 yıllarında Dünya'da ve Türkiye'de yapılmış ve İngilizce olarak 2014-2019 yıllarında yayınlanmış, yaşlı bireylerde uyku bozukluklarını gidermeye yönelik uygulanan nonfarmakolojik müdahaleleri içeren randomize kontrollü çalışmalardır. Çalışmalarda verilerin toplandığı ve yayımlandığı zaman arasındaki süre ortalaması üç yıl olarak bulunmuştur. Ancak araştırmaların bir tanesinde verilerin toplandığı yıl bildirilmemişti. Çalışmalarda toplam 498 kişi yer almıştı. Çalışmalar Dünya'nın beş farklı ülkesinde yapılmıştı. Çalışmalarda verilerin huzurevleri, sağlık bakım merkezleri ve toplum merkezlerinde toplandığı görülmüştür. Çalışmaların örneklem hacminin 54-159 arasında değiştiği belirlenmiştir (Tablo 1).

Yaşlı bireylerde uyku ile ilgili görülen sorunlara yönelik kullanılan yöntemler

Incelenen çalışmalarda yaşlı bireylerde uyku ile ilgili görülen sorunlara yönelik kullanılan yöntemler; bilişsel davranışçı terapi, müzik terapi, anımsama terapisi, fitoterapi (papatya özü), akupres, refleksoloji ve ayak banyosu olarak sıralanmaktadır.

\section{Sonuç Ölçütleri}

Sistematik derlemeye dahil edilen altı çalışmada da uyku kalitesinin belirlenmesi amacıyla PSQI (Pittsburgh Sleep Quality Index) kullanılmıştır.

\section{Müdahale Kategorisine Göre Araştırma Sonuçları}

\section{Zihin Beden Temelli Uygulamalar}

Sistematik derlemeye dahil edilen çalışmaların üçü zihin beden temelli uygulamaları objektif ölçüm teknikleriyle değerlendirmiştir ${ }^{19-21}$. Bu çalışmalarda kullanılan yöntemler bilişsel davranışçı terapi, müzik terapi ve anımsama terapisi olarak sıralanmaktadır. Klinisyen olmayan uyku koçları tarafından sunulan ve altı hafta süren yapılandırılmış bir bilişsel davranışçı terapi programı bireysel ve grup terapisi olmak üzere iki farklı gruba uygulanmış, üçüncü grubun da rutin bakımı sürdürülmüştür. Bireysel ve grup davranışçı terapi müdahalesinin kronik uykusuzluğu olan yaşlı bireylerde uyku kalitesini önemli ölçüde arttırdığı ve uykudaki bu iyileşmenin 12 aya kadar sürdürüldüğü ve iki grup arasında anlamlı bir fark olmadığı belirtilmiştir ${ }^{19}$. Müzik terapinin uyku kalitesine etkisinin PSQI puanı ile değerlendirildiği çalışmada yapılan ön testte bütün katılımcıların uyku kalitesi düşük çıktığı için öncelikle deney ve kontrol grubuna 10-15 dakika süren bir seanslık uyku hijyeni eğitimi verilmiştir. Uyku hijyeni eğitiminin ardından deney grubuna müzik müdahalesi konusunda deneyimli uzmanlar tarafından seçilen Çin enstrümantal klasik müzik, Batı klasik müziği, doğal sesler ve enstrümental klasik şarkıları içeren 169 parçadan oluşan bir listeden katılımcılara seçtiği şarkı üç ay boyunca gecelik 30-45 dakika dinletilmiştir. Sonuçta 1., 2. ve 3. aylarda uyku kalitesinin sürekli iyileştiği sonucu elde edilmiştir ${ }^{20}$. Anımsama terapisi, müdahale grubundaki katılımcılara 25-30 dakika süren bireysel seanslar şeklinde haftada bir kez 12 hafta boyunca uygulanmış, kontrol grubuna herhangi bir girişimde bulunulmamıştır ${ }^{21} .12$ haftanın sonunda yapılan ölçümlerde anımsama terapisinin huzurevinde yaşayan yaşlı bireylerde uyku kalitesi üzerine olumlu etkileri olduğu sonucuna ulaşılmıştır.

\section{Biyolojik Temelli Uygulamalar}

Biyolojik temelli uygulamalardan fitoterapinin kullanıldığı bir çalışmada papatya özünün yaşlı bireylerde uyku kalitesi üzerinde etkinliği değerlendirilmiştir. Bu çalışmada deney grubuna $200 \mathrm{mg}^{\prime} \mid ı k$ papatya özü kapsüllerinden 28 gün boyunca günde iki tane verilmiştir. Kontrol grubundaki katılımcılara ise benzer şekilde buğday kapsülleri (200 mg) verilmiştir. Uyku kalitesi müdahaleden hemen önce, müdahalenin başlamasından iki hafta sonra, müdahalenin tamamlanmasından hemen sonra ve müdahalenin tamamlanmasından iki hafta sonra olmak üzere dört 
ölçümle değerlendirilmiştir. 1 . ve 2 . ölçümlerde deney ve kontrol grupları arasında anlamlı bir fark olmamakla birlikte 3. ve 4. ölçümlerde deney ve kontrol grupları arasındaki fark istatistiksel olarak anlamlı bulunmuştur ${ }^{22}$.

\section{Alternatif Tıbbi Sistemler/Geleneksel Sağlık Sistemleri}

Akupres müdahalesinin uyku kalitesine etkisini inceleyen bir çalışma sistematik derlemeye dahil edilmiştir. Bu çalışmada belirlenen akupunktur noktalarına (Tian-Zhu, Ju-Que, YongQuan, Bai-Hui ve Nei-Guan) uygulanan akupresin huzurevinde yaşayan yaşlı bireylerde uyku kalitesine etkisi ölçülmek istenmiştir. Deney grubuna sekiz hafta, haftada üç kez belirlenen akupunktur noktalarına 24 dakika süreyle aküpres uygulanırken, kontrol grubuna akupunktur noktası olmayan bölgelere deney grubuyla aynı şekilde aküpres uygulanmıştır. Müdahaleden hemen önce, müdahale bittikten sonra ve müdahalenin bitişinde dört hafta sonra uyku kalitesi ölçümleri yapılmıştır. İkinci ve üçüncü ölçümlerde deney ve kontrol gruplarının uyku kalitesi puanlarında anlamlı fark bulunmuş ve belirlenen akupunktur noktalarının uyku kalitesini iyileştirdiği belirtilmiştir ${ }^{23}$.

\section{Manipülatif ve Beden Temelli Uygulamalar}

Manipülatif beden temelli uygulamalardan refleksoloji ve ayak banyosunu içeren bir çalışma sistematik derlemeye dahil edilmiştir. Üç gruplu randomize kontrollü çalışmada bir gruba refleksoloji, bir gruba ayak banyosu ve diğer bir gruba da rutin bakım uygulanmıştır. Refleksoloji uygulaması altı hafta boyunca, haftada bir kez 10 dakika boyunca her ayağa zeytinyağı ile yapılmıştır. Ayak banyosu için katılımcılardan altı hafta boyunca her gece ayağını $41-42^{\circ} \mathrm{C}$ sıcak su ile doldurulmuş $10 \mathrm{~cm}$ yüksekliğinde plastik bir kaba yerleştirmeleri istenmiştir. Ayak banyosu uyku saatlerinden bir saat önce 20 dakika süreyle yapılmıştır. Bu çalışmaya göre refleksoloji ve ayak banyosu uygulaması, yaşlı bireylerde uyku kalitesini müdahale öncesi uyku kalitesine göre arttıran iki ayrı uygulama olarak belirtilmektedir ${ }^{24}$.

\section{TARTIŞMA}

Bu sistematik derlemede, yaşlı bireylerde uyku sorunlarını gidermeye yönelik kullanılan nonfarmakolojik yöntemler ve uyku kalitesine etkisine dair mevcut ampirik kanıtlar özetlenmiştir. Sistematik derlemeye dahil edilen çalışmalarda değerlendirilen yöntemler; bilişsel davranış̧̧ı terapi, müzik terapi, anımsama terapisi, papatya özü, akupres, refleksoloji ve ayak masajı şeklinde sıralanmaktadır. Bu yöntemlerin hepsinin uygulama öncesine göre uyku kalitesini arttırıcı etkisi olduğu bulunmuştur.

Uyku kalitesine etkisi bulunan uygulamalardan biri bilişsel davranışçı terapidir. Bilişsel davranışçı terapi; düşüncelerimizin, ne hissettiğimiz ve nasıl davrandığımızı belirlediğini vurgulayan yapılandırmış bir terapi şeklidir ${ }^{25}$. Alessi ve diğerleri (2016)'nin uyguladığı bilişsel davranışçı terapi programı; uyaran kontrolü, uyku kısıtlaması, bilişsel terapi ve uyku hijyeni konularında verilen eğitimleri kapsamaktaydı. Bu programın, uyku kalitesini önemli ölçüde arttırdığı ve uykudaki bu iyileşmenin 12 aya kadar sürdürüldüğü belirtilmiştir ${ }^{19}$. Buna paralel olarak uyku bozukluğu olan yaşı bireylerde bilişsel davranışçı terapinin terapötik etkilerinin incelendiği bir çalışmada tedaviden hemen sonra ve üç aylık izlemde uyku kalitesinde iyileşmeler olduğu bildirilmiştir ${ }^{26}$. Bilişsel davranış̧̧ terapinin kronik uykusuzluk probleminde kullanılacak etkili bir yöntem olduğuna yönelik güçlü kanıtlar bulunmaktadır ${ }^{27}$.

Müzik terapi uyku kalitesini arttırmak amacıyla sıklıkla kullanılan bir yöntem olarak karşımıza çıkmaktadır ${ }^{28,29}$. Müzik terapi vücut hızını yavaşlatma ve otonom sinir sistemini ayarlama (sempatik sistemi baskılamak ve parasempatik sistemi etkinleştirmek gibi) etkisi nedeniyle uyku kalitesini etkilediği bilinmektedir ${ }^{30}$. Bu sistematik derlemede müzik terapinin uyku kalitesini iyileştirmede etkili bir yöntem olduğu görülmektedir ${ }^{20}$. Literatürde bunu destekleyen çalışmalar mevcuttur ${ }^{31,32}$.

Anımsama terapisinin bilişsel işlev, hafıza ve yaşam kalitesi üzerine olumlu etkilerinin olduğu bilinmektedir ${ }^{24}$. Duru Aşiret, 2018'in çalışmasında anımsama terapisinin uyku kalitesi üzerine etkileri değerlendirilmiş ve uyku kalitesini arttırdığı yönünde bulgular elde edilmiştir. Literatürde anımsama terapisinin uyku kalitesi üzerine etkilerini değerlendiren çalışmalar kısıtlı olmakla birlikte uyku problemlerinde etkili bir yöntem olduğu bildirilmektedir ${ }^{33,34}$. Alzheimer tanısı olan bireylerde anımsama terapisinin günlük yaşam aktivitelerine etkisini değerlendirdiği çalışmada ise uyku boyutunda bir değişim yaratmadığı bildirilmişti ${ }^{35}$.Fitoterapi uyku kalitesini arttırmak için yaygın kullanılan bir yöntemdir. Tart kiraz suyu, papatya özü, kırmızı adaçayı, melek otu, mandalina, kullanılan yöntemlerden bazılarıdır ${ }^{36,37}$. Bu sistematik derlemeye dahil edilen çalışmada papatya özünün yaşlı bireylerde uyku kalitesine etkisi değerlendirilmiş ve uyku kalitesini önemli ölçüde arttırabileceği belirtilmiştir ${ }^{22}$. Katılımcılar 28 gün boyunca papatya özü kapsüllerini kullanmıştır. İki hafta sonra yapılan ölçümlerde deney ve kontrol gruplarında anlamlı fark olmamakla birlikte 4 ve 6 . haftaların sonunda yapılan ölçümlerde papatya özü kullananların uyku kalitesinde anlamlı şekilde iyileşme olduğu bulunmuştur. Katılımcılara iki hafta boyunca papatya çayı içirilmesinin uyku kalitesine etkisinin değerlendirildiği bir diğer çalışmada iki haftanın sonunda uyku kalitesinde iyileşmeler gözlenmiş. Ancak dört hafta sonunda yapılan ölçümlerde uyku kalitesindeki iyileşme gözlenmemiştir ${ }^{38}$. Literatürde papatyanın kısa vadede uyku kalitesini iyileştirmede güvenli bir yöntem olduğunu belirten bir meta-analiz çalışması bulunmaktadır ${ }^{39}$.

Akupres, vücuttaki belirli noktalara basıncın uygulandığı geleneksel bir yöntemdir ${ }^{40}$. Akupres; ağrı, öksürük, konstipasyon, obezite, dismenore, depresyon, anksiyete ve uyku bozuklukları gibi durumlarda kullanılmaktadır ${ }^{41-44}$. Belirlenen akupunktur noktalarına (Tian-Zhu, Ju-Que, YongQuan, Bai-Hui ve Nei-Guan) uygulanan akupresin huzurevinde yaşayan yaşlı bireylerde uyku kalitesini artırabileceği belirtilmiştir ${ }^{23}$. Literatürde de akupresin, farklı hastalarda yan etki oluşturmadan algılanan uyku kalitesini iyileştirme potansiyeline sahip bir yöntem olduğu vurgulanmaktadır ${ }^{40}$. 
Tablo 1. Sistematik Derlemeye Alınan Randomize Kontrollü Çalışmaların Özellikleri

\begin{tabular}{|c|c|c|c|c|c|c|c|c|c|c|}
\hline & Yazarlar, Yıl & $\begin{array}{l}\text { Çalışma } \\
\text { nın } \\
\text { yapıldığı } \\
\text { yıl }\end{array}$ & $\begin{array}{l}\text { Çalışmanın } \\
\text { deseni }\end{array}$ & $\begin{array}{l}\text { Veri Toplama } \\
\text { Aracı }\end{array}$ & Ülke & $\begin{array}{l}\text { Çalışma } \\
\text { Alanı }\end{array}$ & $\begin{array}{l}\text { Örneklem } \\
\text { Hacmi }\end{array}$ & Yaş & $\begin{array}{l}\text { Uygulanan } \\
\text { Yöntem }\end{array}$ & Bulgular \\
\hline 1 & $\begin{array}{l}\text { Valizadeh ve } \\
\text { ark. } 2015\end{array}$ & 2013 & $\begin{array}{l}\text { Randomize } \\
\text { konrollü deney }\end{array}$ & PSQI & İran/Tabris & $\begin{array}{l}\text { Sağlık } \\
\text { Bakım } \\
\text { Merkezi }\end{array}$ & $\begin{array}{l}\text { Deney } \\
\text { (Refleksoloji) } \\
: 23 \\
\text { Deney (Ayak } \\
\text { banyosu): } 23 \\
\text { Kontrol } \\
\text { (Rutin } \\
\text { bakım): } 23 \\
\end{array}$ & $\begin{array}{l}60-75 \\
\text { yaş }\end{array}$ & $\begin{array}{l}\text { Refleksoloji } \\
\text { Ayak } \\
\text { banyosu } \\
\text { Rutin bakım }\end{array}$ & $\begin{array}{l}\text { Sonuçlar, refleksoloji ve ayak banyosu gruplarında } \\
\text { öncekine kıyasla müdahale sonrası PSQ puanlarının } \\
\text { istatistiksel olarak anlamlı olduğunu göstermiş } \\
\text { ( } p=0.01, p=0.001) \text {; ancak, kontrol grubunda } \\
\text { istatistiksel olarak anlamlı bir fark görülmemiş } \\
(p=0.14) \text {. }\end{array}$ \\
\hline 2 & $\begin{array}{l}\text { Alessi ve ark } \\
2016\end{array}$ & $\begin{array}{l}2010- \\
2013\end{array}$ & $\begin{array}{l}\text { Randomize } \\
\text { konrollü deney }\end{array}$ & PSQI & $A B D$ & $\begin{array}{l}\text { Gazi İşleri } \\
\text { Bakanlığı } \\
\text { Sağlık } \\
\text { Sistemi }\end{array}$ & $\begin{array}{l}\text { Deney (Grup } \\
\text { Bilişsel } \\
\text { davranışçı } \\
\text { terapi): } 52 \\
\text { Deney } \\
\text { (Bireysel } \\
\text { Bilişsel } \\
\text { davranış̧̧ı } \\
\text { terapi): } 54 \\
\text { Kontrol } \\
\text { (Rutin } \\
\text { bakım): } 53 \\
\end{array}$ & $\begin{array}{l}60 \text { yaş } \\
\text { ve } \\
\text { üzeri }\end{array}$ & $\begin{array}{l}\text { Grup bilişsel } \\
\text { davranışçı } \\
\text { terapi } \\
\text { Bireysel } \\
\text { bilişsel } \\
\text { davranışçı } \\
\text { terapi } \\
\text { Rutin bakım }\end{array}$ & $\begin{array}{l}\text { Müdahale grubunda, bireysel ve grup bilişsel } \\
\text { davranışı̧ı terapi alan bireyler arasında herhangi bir } \\
\text { zaman noktasında PSQı puanlarında anlamlı bir fark } \\
\text { bulunmamış (p>0.12). } \\
\text { Klinisyen olmayan uyku koçları tarafından verilen } \\
\text { yapılandırılmış, manuel tabanlı bir bilişsel davranış̧̧ı } \\
\text { terapi programı, kronik uykusuzluğu olan yaşı } \\
\text { bireylerde PSQı puanı ile değerlendirilen uyku } \\
\text { kalitesini anlamlı ölçüde arttırmış ve uykudaki bu } \\
\text { iyileşme } 12 \text { aya kadar sürdürülmüş. }\end{array}$ \\
\hline 3 & $\begin{array}{l}\text { Wang ve ark. } \\
2016\end{array}$ & $\begin{array}{l}2011- \\
2012\end{array}$ & $\begin{array}{l}\text { Randomize } \\
\text { konrollü deney }\end{array}$ & PSQI & $\begin{array}{l}\text { Shaanxi/ } \\
\text { China }\end{array}$ & $\begin{array}{l}\text { Kentsel } \\
\text { Toplum } \\
\text { Merkezi }\end{array}$ & $\begin{array}{l}\text { Deney (müzik } \\
\text { terapi ve } \\
\text { uyku hijyeni } \\
\text { eğitimi): } 32 \\
\text { Kontrol (uyku } \\
\text { hijyeni } \\
\text { eğitimi): } 32\end{array}$ & $\begin{array}{l}60 \text { yaş } \\
\text { ve } \\
\text { üzeri }\end{array}$ & $\begin{array}{l}\text { Müzik terapi } \\
\text { Uyku hijyeni } \\
\text { eğitimi }\end{array}$ & $\begin{array}{l}\text { Müdahale grubu, PSQI skorunun başlangıçta } 13.53,1 \\
\text { ayda } 9.28,2 \text { ayda } 8.28 \text { ve } 3 \text { ayda } 7.28 \text { olması ile uyku } \\
\text { kalitesinde sürekli iyileşmeler görülmüş ( } p<0.05 \text { ). } \\
\text { Kontrol grubunun PSQ skoru da başlangıçta } \\
12.26 \text { 'dan } 3 \text { ayda } 8.72 \text { 'ye düşmüş ancak müdahale } \\
\text { grubu her ölçümde daha büyük iyileşmeler elde etmiş } \\
\text { ( } p<0.05 \text { ). }\end{array}$ \\
\hline 4 & $\begin{array}{l}\text { Adib- } \\
\text { Hajbaghery } \\
\text { ve Mousavi } \\
2017\end{array}$ & 2016 & $\begin{array}{l}\text { Randomize } \\
\text { konrollü deney }\end{array}$ & PSQI & Karai/ Iran & Huzurevi & $\begin{array}{l}\text { Deney } \\
\text { (papatya } \\
\text { özü):30 } \\
\text { Kontrol } \\
\text { (buğday unu } \\
\text { kapsülü): } 30\end{array}$ & $\begin{array}{l}60 \text { yaş } \\
\text { ve } \\
\text { üzeri }\end{array}$ & $\begin{array}{l}\text { Papatya özü } \\
\text { Buğday unu } \\
\text { kapsülü }\end{array}$ & $\begin{array}{l}\text { 1. ve } 2 \text {. ölçümlerde deney ve kontrol grupları arasında } \\
\text { ortalama PSQI skorunda istatistiksel olarak anlamlı } \\
\text { fark bulunmamış (sırasıyla } p=0.639 \text { ve } 0.142 \text { ), } 3 \text {. ve } 4 \text {. } \\
\text { ölçümde ise bu farklar istatistiksel olarak anlamlı } \\
\text { bulunmuş (sırasıyla } p=0.007 \text { ve } 0.002 \text { ). }\end{array}$ \\
\hline 5 & $\begin{array}{l}\text { Lai ve ark } \\
2017\end{array}$ & Belirsiz & $\begin{array}{l}\text { Randomize } \\
\text { konrollü deney }\end{array}$ & PSQI & Taiwan & Huzurevi & $\begin{array}{l}\text { Deney } \\
\text { (akupres): } 31 \\
\text { Kontrol } \\
\text { (sahte } \\
\text { akupunktur } \\
\text { noktalarına } \\
\text { akupres } \\
\text { uygulaması): } \\
31\end{array}$ & $\begin{array}{l}65 \text { yaş } \\
\text { ve } \\
\text { üzeri }\end{array}$ & $\begin{array}{l}\text { Akupres } \\
\text { Sahte } \\
\text { akupres }\end{array}$ & $\begin{array}{l}\text { Müdahale sonrası yapılan iki ölçümde de deney grubu } \\
\text { ile kontrol grubu PSQı puanları arasında istatistiksel } \\
\text { olarak anlamlı fark bulunmuş }(p<0.001) \text {. }\end{array}$ \\
\hline 6 & $\begin{array}{l}\text { Duru Aşiret } \\
2018\end{array}$ & 2017 & $\begin{array}{l}\text { Randomize } \\
\text { konrollü deney }\end{array}$ & PSQI & Turkey & Huzurevi & $\begin{array}{l}\text { Deney } \\
\text { (Anımsama } \\
\text { terapisi): } 28 \\
\text { Kontrol } \\
\text { (Rutin } \\
\text { bakım): } 26\end{array}$ & $\begin{array}{l}65 \text { yaş } \\
\text { ve } \\
\text { üzeri }\end{array}$ & $\begin{array}{l}\text { Anımsama } \\
\text { terapisi }\end{array}$ & $\begin{array}{l}\text { Deney ve kontrol gruplarının müdahale sonrası PSQI } \\
\text { skorları arasında istatistiksel olarak anlamlı bir fark } \\
\text { bulunmuş ( } p<0.05) \text {. Müdahale grubunun en son } \\
\text { ortanca skoru kontrol grubundan daha düşük } \\
\text { bulunmuş. }\end{array}$ \\
\hline
\end{tabular}


Manipülatif beden temelli uygulamalardan refleksoloji uygulamasında ayaklardaki sinir uçlarına uygulanan bir basınç vücudun belirli bölümlerinde sensör görevi görmektedir ve bu sensörlerin kan dolaşımını arttırma, enerji verme, gevşetme ve homeostazı sürdürme gibi etkisi vardır$^{45}$. Ilık su ile yapılan bir ayak banyosunun uyku kalitesine etkisi ise sirkadiyen vücut ISISI ritmiyle ilişkilendirilmiştir. Buna göre çekirdek (rektal) vücut sıcaklığı uykudan uyanınca en düşük seviyededir ve gün boyu yükselmektedir. Uyku başlangıcından önce ise sabah ulaşacağı en düşük noktaya doğru düşmeye başlar. Uykudan önce eller ve ayaklara sıcak uygulama yapmak periferik sıcaklık ile çekirdek sıcaklık arasındaki farkı arttırmakta ve bu da uykunun başlamasını kolaylaştırabilmektedir ${ }^{46}$. Bu sistematik derlemeye dahil edilen çalışmada refleksoloji ve ayak banyosu uygulamalarının, uyku kalitesini arttırmada ayrı ayrı etkili yöntemler olduğu belirtilmiştir ${ }^{24}$. Literatürde uyku kalitesini arttırmada refleksolojinin sırt masajından daha etkili bir uygulama olduğunu belirten bir çalışma bulunurken ${ }^{47}$, uyku kalitesini iyileştirmede refleksoloji ve ayak banyosu uygulamalarının birlikte yapılmasının ayrı ayrı yapılmasından daha etkili olduğunu bildiren bir çalışmaya da ulaşılmıştır ${ }^{48}$.

\section{SONUÇ ve ÖNERILER}

Bu sistematik derleme ile yaşlı bireylerde uyku sorunlarını gidermeye yönelik kullanılan nonfarmakolojik müdahaleler incelenmiştir. Derlemeye dahil edilen çalışmalarda uygulanan yöntemlerin hiçbir yan etkisi bildirilmemiştir. Kullanılan altı yöntemde de uyku kalitesinde iyileşmeler olduğu görülmektedir. İncelenen bu yöntemler zihinsel ve fiziksel sağlığı etkileyerek uyku kalitesini arttırmaktadır. Bu yöntemler uyku sorunlarını gidermeye yönelik kolaylıkla kullanılacak yöntemlerdir. Çalışmaların örneklem sayılarının düşük olması genellenebilirliği azaltmaktadır. Kullanılan yöntemlerin uzun süreli etkilerinin bilinmesi için bundan sonra yapılacak çalışmalarda daha uzun süreli izlem yapılması önerilmektedir. Bu çalışmaların tekrarlanıp dahagüçlü kanıtların sunulmasına ihtiyaç vardır.

Etik Kurul Onayı: -

Çıkar Çatışması: Yoktur.

Finansal Destek: Bildirilmemiştir.

Katılımcı Onamı: -

Yazar katkıları:

Araştıma dizaynı: $\mathrm{GB}, \mathrm{FH}$

Veri toplama: $\mathrm{GB}, \mathrm{FH}$

Veri analizi: $\mathrm{GB}, \mathrm{FH}$

Makale yazımı: GB, FH

Teşekkür: -

Ethics Committee Approval: -

Confict of Interest: Not reported.

Funding: None.

Exhibitor Consent: -

Author contributions:

Study design: $\mathrm{GB}, \mathrm{FH}$

Data collection: $\mathrm{GB}, \mathrm{FH}$

Data analyses: $\mathrm{GB}, \mathrm{FH}$

Drafting manuscript: $\mathrm{GB}, \mathrm{FH}$

Acknowledgement: -

\section{KAYNAKLAR}

1. Hernandez $A B$, Feinsilver $S H$. Sleep in the Elderly: Normal and Abnormal. Pandi-Perumal SR. Synopsis Of Sleep Medicine. USA: Apple Academic Press Inc; 2017.

2. Zalai D, Bingeliene A, Shapiro C. Sleepiness in the Elderly. Sleep Med Clin. 2017;12(3):429-41.

3. Gooneratne NS, Vitiello MV. Sleep in older adults: normative changes, sleep disorders, and treatment options. Clin Geriatr Med. 2014;30(3):591-627.

4. Luo J, Zhu G, Zhao Q, Guo Q, Meng H, Hong Z. et al. Prevalence and risk factors of poor sleep quality among chinese elderly in an urban community: Results from the Shanghai aging study. PLoS ONE. 2013;8(11):10-17.

5. Gindin J, Shochat T, Chetrit A, Epstein S, Ben Israel Y, Levi $S$ et al. Insomnia in long-term care facilities: a comparison of seven european countries and Israel: the services and health for elderly in long term care study. J Am Geriatr Soc. 2014;62(11):2033-39.

6. Demir G, Özen B, Zincir H, Bulucu-Boyuksoy GD. Sleep quality in elderly individuals and related factors Sleep quality. J Clin Anal Med. 2018;9(2):97-101.

7. Soykök G, Yılmaz R, Şentürk Ai, Çevimk Ş, Figül Gökçe Ş, Kayım Yıldız Ö et al. Association of sleep quality and daytime sleepiness with cognition in the elderly. Turkish Journal of Geriatrics. 2015;18(2):123-29.

8. Jaussent I, Empana JP, Ancelin ML, Besset A, Helmer $C$, Tzourio $C$, et al. Insomnia, daytime sleepiness and cardio-cerebrovascular diseases in the elderly: a 6year prospective study. PLoS ONE. 2013;8(2).

9. Kim WH, Kim BS, Kim SK, Chang SM, Lee DW, Cho MJ, Bae JN. Prevalence of insomnia and associated factors in a community sample of elderly individuals in South Korea. Int Psychogeriatr. 2013;25(10),172937.

10. Makic MBF, Rauen C, Watson R, Poteet AW. Examining the evidence to guide practice: challenging practice habits. Crit Care Nurse. 2014;34(2):28-5.

11. Auld F, Maschauer EL, Morrison I, Skene DJ, Riha RL. Evidence for the efficacy of melatonin in the treatment of primary adult sleep disorders. Sleep medicine reviews. 2017;34:10-22.

12. Fayazi S, Babashahi $M$, Rezaei $M$. The effect of inhalation aromatherapy on anxiety level of the patients in preoperative period. Iran J Nurs Midwifery Res. 2011;16(4):278-83.

13. Bikmoradi A, Seifi Z, Poorolajal J, Araghchian M, Safiaryan R, Oshvandi K. Effect of inhalation aromatherapy with lavender essential oil on stress and vital signs in patients undergoing coronary artery bypass surgery: A single-blinded randomized clinical trial. Complement Ther Med. 2015;23(3):331-38.

14. Midilli TS, Eşer i, Yücel Ş. The use of nonpharmacological methods in pain management of nurses working in surgical clinics and factors 
affecting their use. Acıbadem Üniversitesi Sağlık Bilimleri Dergisi. 2019;10(1):60-6.

15. Du S, Dong J, Zhang H, Jin S, Xu G, Liu Z, et al. Taichi exercise for self-rated sleep quality in older people: A systematic review and meta-analysis. Int J Nurs Stud. 2015;52:368-379.

16. Shang B, Yin H, Jia Y, Zhao J, Meng X, Chen L, et al. Nonpharmacological interventions to improve sleep in nursing home residents: A systematic review. Geriatr Nurs. 2019;40(4):405-16.

17. Karaçam Z. Sistematik derleme metodolojisi: Sistematik derleme hazırlamak için bir rehber. Dokuz Eylül Üniversitesi Hemşirelik Fakültesi Elektronik Dergisi. 2014;6(1):26-33.

18. Joanna Briggs Institute. Checklist for Randomized Controlled Trials. Critical Appraisal tools. 2019;1-9.

19. Alessi C, Martin JL, Fiorentino L, Fung CH, Dzierzewski JM, Rodriguez Tapia JC, et al. Cognitive Behavioral Therapy for Insomnia in Older Veterans Using Nonclinician Sleep Coaches: Randomized Controlled Trial. J Am Geriatr Soc. 2016;64(9):1830-38.

20. Wang Q, Chair SY, Wong EML, Li X. The Effects of Music Intervention on Sleep Quality in CommunityDwelling Elderly. J Altern Complement Med. 2016;22(7):576-584.

21. Duru Aşiret G. Effect of reminiscence therapy on the sleep quality of the elderly living in nursing homes: A randomized clinical trial. Eur J Integr Med.. 2018;20:1-5.

22. Adib-Hajbaghery $M$, Mousavi SN. The effects of chamomile extract on sleep quality among elderly people: A clinical trial. Complement Ther Med. 2017;25:109-14.

23. Lai FC, Chen IH, Chen PJ, Chen IJ, Chien HW, Yuan CF. Acupressure, Sleep, and Quality of Life in Institutionalized Older Adults: A Randomized Controlled Trial. J Am Geriatr Soc. 2017;65(5):103-8.

24. Valizadeh L, Seyyedrasooli A, Zamanazadeh V, Nasiri K. Comparing the Effects of Reflexology and Footbath on Sleep Quality in the Elderly: A Controlled Clinical Trial. Iran Red Crescent Med J. 2015;17(11):1-8.

25. Özcan Ö, Gül Çelik G. Bilişsel Davranışçı Terapi. Turkiye Klinikleri J Child Psychiatry-Special Topics. 2017;3(2):115-20.

26. Lovato N, Lack L, Kennaway DJ. Comparing and contrasting therapeutic effects of cognitive-behavior therapy for older adults suffering from insomnia with short and long objective sleep duration. Sleep Med. 2016;22:4-12.

27. Trauer JM, Qian MY, Doyle JS, Rajaratnam SMW, Cunnington D. Cognitive behavioral therapy for chronic insomnia: A systematic review and metaanalysis. Ann Intern Med. 2015;163(3):191-204.

28. Jespersen K, Koenig J, Jennum P, Vuust P. Music for insomnia in adults (Review). Cochrane Database of Systematic Reviews. 2015;(8):2-4.

29. Meghani N, Tracy MF, Hadidi NN, Lindquist R. Part II: The Effects of Aromatherapy and Guided Imagery for the Symptom Management of Anxiety, Pain, and
Insomnia in Critically III Patients: An Integrative Review of Current Literature. Dimens Crit Care Nurs. 2017;36(6):334-48.

30. Nilsson $U$. Soothing music can increase oxytocin levels during bed rest after open-heart surgery: a randomised control trial. J Clin Nurs. 2009;8:2153-61.

31. Shum A, Taylor BJ, Thayala J, Chan MF. The effects of sedative music on sleep quality of older communitydwelling adults in singapore. Complement Ther Med. 2014;22(1):49-56.

32. Huang $\mathrm{CY}$, Chang ET, Lai HL. Comparing the effects of music and exercise with music for older adults with insomnia. Appl Nurs Res. 2016;32:104-10.

33. Sok SR. Effects of individual reminiscence therapy for older women living alone. Int Nurs Rev. 2015;62(4):517-24.

34. Musavi M, Mohammadian S, Mohammadinezhad B. The effect of group integrative reminiscence therapy on mental health among older women living in Iranian nursing homes. Nurs Open. 2017;4(4):303-9.

35. Duru Aşiret G, Kapucu S. The Effect of Reminiscence Therapy on Cognition, Depression, and Activities of Daily Living for Patients with Alzheimer Disease. J Geriatr Psychiatry Neurol. 2016;29(1):31-7.

36. Singh A, Zhao K. (2017). Treatment of Insomnia With Traditional Chinese Herbal Medicine. Int Rev Neurobiol. 2017;135:97-115

37. Losso J, Finley JW, Karki N, Liu AG, Prudente A, Tipton $R$, et al. Pilot Study of the Tart Cherry Juice for the Treatment of Insomnia and Investigation of Mechanisms. Am J Ther. 2018;25(2):194-201.

38. Chang $\mathrm{SM}$, Chen $\mathrm{CH}$. Effects of an intervention with drinking chamomile tea on sleep quality and depression in sleep disturbed postnatal women: A randomized controlled trial. J Adv Nurs. 2016;72(2):306-15.

39. Hieu TH, Dibas M, Surya Dila KA, Sherif NA, Hashmi MU, Mahmoud $M$, et al. Therapeutic efficacy and safety of chamomile for state anxiety, generalized anxiety disorder, insomnia, and sleep quality: A systematic review and meta-analysis of randomized trials and quasi-randomized trials. Phytother Res. 2019;33(6):1604-15.

40. Waits A, Tang YR, Cheng HM, Tai CJ, Chien LY. Acupressure effect on sleep quality: A systematic review and meta-analysis. Sleep Med Rev. 2018;37:24-34.

41. Hmwe NTT, Subramanian P, Tan LP, Chong WK. The effects of acupressure on depression, anxiety and stress in patients with hemodialysis: A randomized controlled trial. Int J Nurs Stud. 2015;52(2):509-18.

42. Cha NH, Sok SR. Effects of Auricular Acupressure Therapy on Primary Dysmenorrhea for Female High School Students in South Korea. J Nurs Scholarsh. 2016;48(5):508-16.

43. Liu XR, Feng L, Nicole R, Wong NS. Effects of auricular acupressure therapy for preventing constipation in leukemia patients undergoing chemotherapy: 
Protocol for a systematic review. Eur J Integr Med. 2017;15:42-6.

44. Mehta P, Dhapte V, Kadam S, Dhapte V. Contemporary acupressure therapy: Adroit cure for painless recovery of therapeutic ailments. J Tradit Complement Med. 2017;7(2):251-63.

45. Rambod M, Pasyar N, Shamsadini M. The effect of foot reflexology on fatigue, pain, and sleep quality in lymphoma patients: A clinical trial. Eur J Oncol Nurs. 2019;43:101678.

46. Liao WC, Chiu MJ, Landis CA. A warm footbath before bedtime and sleep in older Taiwanese with sleep disturbance. Res Nurs Health. 2008;31(5):514-28.

47. Unal KS, Balci Akpinar R. The effect of foot reflexology and back massage on hemodialysis patients' fatigue and sleep quality. Complement Ther Clin Pract. 2016;24:139-44.

48. Rahmani A, Naseri M, Salaree MM, Nehrir B. Comparing the Effect of Foot Reflexology Massage, Foot Bath and Their Combination on Quality of Sleep in Patients with Acute Coronary Syndrome. J Caring Sci. 2016;5(4):299-306. 